Editorial

\title{
Acknowledgement to Reviewers of Human Population Genetics and Genomics
}

HPGG Editorial Office

4505 Pacific HWY E, Fife, WA 98424, USA; E-Mail: hpgg@pivotscipub.com

Received: 17 Dec 2021

Accepted: 18 Dec 2021

Published: 24 Dec 2021

Copyright: (c) 2021 by the author(s). This is an Open Access article distributed under the terms of the Creative Commons License Attribution 4.0 International (CC BY 4.0), which permits unrestricted use, distribution, and reproduction in any medium or format, provided the original work is correctly credited.

Publisher's Note: Pivot Science Publication Corp. remains neutral with regard to jurisdictional claims in published maps and institutional affiliations.
On behalf of the entire journal team, we would like to express our gratitude to the scientists who contributed their valuable expertise and time in reviewing manuscripts for the journal Human Population Genetics and Genomics.

Peer review is one of the most important processes that we rely on for assessing the quality of submissions. The reviewer's comments have been key to improving the quality of the papers published in Human Population Genetics and Genomics. We greatly appreciate the following reviewers for their generous support of Human Population Genetics and Genomics in 2021.

Note: This list reflects reviews received between January 1, 2021 and December 20, 2021; names listed in alphabetical order.

$$
\begin{aligned}
& \text { Lee Cronk } \\
& \text { Cesare de Filippo } \\
& \text { Paolo Menozzi } \\
& \text { Etienne Patin } \\
& \text { Irina Pugach } \\
& \text { Ryan Raaum }
\end{aligned}
$$

Jorge Rocha

Naruya Saitou

Alicia Sanchez-Mazas

Rémi Tournebize

Ke Wang

Justin Yeh

Cite this article: HPGG Editorial Office. Acknowledgement to Reviewers of Human Population Genetics and Genomics. Hum Popul Genet Genom. 2021;1,1. https://doi.org/10.47248/hpgg2101010006. 